\title{
Fluctuations of the non-Newtonian fluid flow in a Kenics static mixer: An experimental study
}

\author{
Sylwia Peryt-Stawiarska, Zdzisław Jaworski \\ Szczecin University of Technology, Institute of Chemical Engineering and Environmental Protection Processes, al. Piastów \\ 42, 71-065 Szczecin, Poland; e-mail: peryt@ps.pl
}

\begin{abstract}
The measurements for a Kenics static mixer were carried out using Laser Doppler Anemometer (LDA). The test fluid was non-Newtonian solution of CMC, Blanose type $9 \mathrm{H} 4$. The velocity data inside the $5^{\text {th }}$ Kenics insert were collected for the axial components at five levels of Reynolds number, $\mathrm{Re}=20 \div 120$. Velocity fluctuations were also analyzed in the frequency domain, after processing them with the help of the Fast Fourier Transform (FFT) procedure. The spectra of fluctuations provided information about level of the fluctuations in the observed range of Reynolds number. The obtained data were then also used to plot the velocity profiles for the fifth insert of the Kenics mixer. It was concluded that in the investigated range of Reynolds numbers $(\mathrm{Re}=20 \div 120)$ a strong dependence of the velocity profiles and the flow fluctuations on Reynolds number was observed.
\end{abstract}

Keywords: Flow instabilities, LDA measurements, non-Newtonian fluid, Kenics mixer.

The work was presented at the $11^{\text {th }}$ Polish Seminar on Mixing in Rogów--ódź, September 15-18, 2008.

\section{INTRODUCTION}

Two different types of mixers, stirred tanks or static mixers, are nowadays commonly used in broad range of industrial applications. Detailed knowledge of the hydrodynamics in such devices is vital to control the mixing process in the most effective way. Such an analysis for the static mixer was done in the past, among others, by van Wageningen et al. ${ }^{1}$ or Wadley and Dawson ${ }^{2}$. Jaffer and Wood ${ }^{3}$ performed investigation of the mixing efficiency for two fluids inside the Kenics static mixer. Authors presented analysis of the velocity fields especially from the perspective of the eddy structures appearing in the flow. Critical values of the Reynolds number were also presented. Adamiak and Jaworski ${ }^{4}$ performed the LDA experiment for non-Newtonian fluid flow inside the Kenics static mixer. The investigated range of Reynolds number was from 160 to 640. Authors observed for $\mathrm{Re}=640$ strong increase of the fluctuations of the axial velocity reaching even $40 \%$ of the mean value. Based on experimental measurements (LDA) of the axial velocity inside the Kenics and SMX inserts Adamiak ${ }^{5}$ concluded that velocity field was loosing its laminar character for Reynolds number $\mathrm{Re}>100$ for Newtonian fluid and $\mathrm{Re}>10$ for nonNewtonian fluid.

Fang and Lee ${ }^{6}$ observed, based on pressure drop measurements, that for the Kenics static mixer transition from laminar to turbulent motion may occur for critical Reynolds number $\mathrm{Re}=150$. On the other hand Li et al. ${ }^{7}$ concluded that in the SMX mixer transitional flow takes place for the broad range of Reynolds numbers from 15 to 1000. This range was obtained based on the experimental measurements of the pressure drop.

The presented study aims at shedding more light on the non-Newtonian liquid flow instabilities occurring inside a Kenics static mixer. Such an experimental evidence should enhance our fundamental knowledge of the mixing mechanism and would also provide a basis for validation of momentum transfer simulations by Computational Fluid Dynamics (CFD) codes.

\section{EXPERIMENTAL SETUP}

The measurements for a Kenics static mixer were carried out using Laser Doppler Anemometer (LDA) produced by TSI Inc. Six Kenics (Fig. 1) inserts were located inside the test tube.

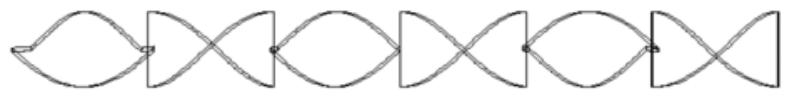

Figure 1. The Kenics static mixer

In order to ensure fully developed flow conditions, the main velocity data were collected both for the fifth insert downstream the first insert and also well upstream for checking the inlet conditions. LDA measurements were carried out with use of the experimental setup presented in Fig. 2.

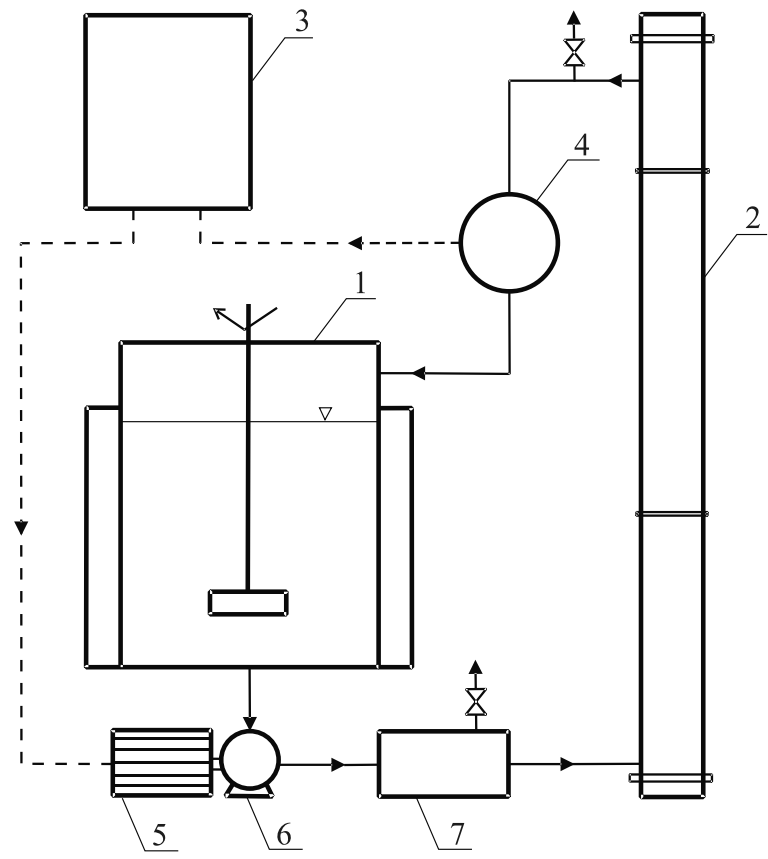

Figure 2. The experimental rig: 1 - storage vessel, 2 - static mixer tube with test section, 3 - flow control unit, 4 - electromagnetic flow meter, 5 - motor, 6 helical pump, 7 - pulsation damper 
The test fluid was non-Newtonian solution of CMC, Blanose type $9 \mathrm{H} 4$ (Carboxymethylocellulose, $n \approx 0.59$; $\left.k \approx 0.19\left[\mathrm{~Pa} \cdot \mathrm{s}^{\mathrm{n}}\right]\right)$. The velocity data inside the $5^{\text {th }}$ Kenics insert were collected for the axial and tangential components at five levels of Reynolds number, $\operatorname{Re}=20 ; 40 ; 60$; $80 ; 120$. Reynolds number was calculated from the equation:

$$
\operatorname{Re}=\frac{D^{n} \cdot w^{2-n} \cdot \rho}{\frac{k}{8}\left(\frac{6 n+2}{n}\right)^{n}}
$$

where $D$ was diameter of the pipe, $w$ - velocity of the fluid, $\rho$-density, $n, k$ - rheological parameters.

Velocity fluctuations were also analyzed in the frequency domain, after processing them with the help of the Fast Fourier Transform (FFT) procedure.

The measurements were carried out at five measurement points, however, the FFT analysis was performed only for two points: $\mathrm{R}=0,0306 \mathrm{~m}$ and $\mathrm{R}=0,0244 \mathrm{~m}$. At the radial positions of $\mathrm{R}<0,0244 \mathrm{~m}$ the LDA readings were not recorded due to certain opaqueness of the CMC solution, which resulted in weak optical signals received from locations close to the mixer axis.

\section{RESULTS AND DISCUSSION}

The obtained from LDA data were used to plot the velocity (a) and velocity fluctuations (b) profiles for the fifth insert of the Kenics mixer at different levels of Reynolds number (Fig. 3).

CMC, KM, L 1/2, $\alpha=60^{\circ}, R=0,0306 m$
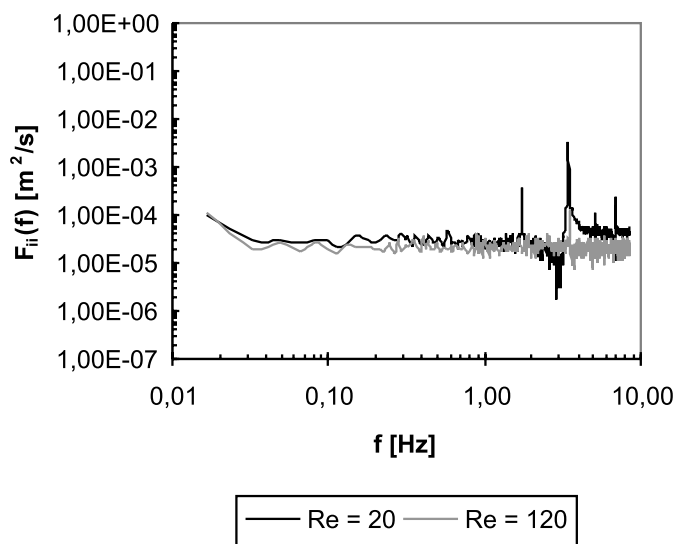

$\mathrm{CMC}, \mathrm{KM}, \mathrm{L} 1 / 2, \alpha=90^{\circ}, \mathrm{R}=0,0306 \mathrm{~m}$

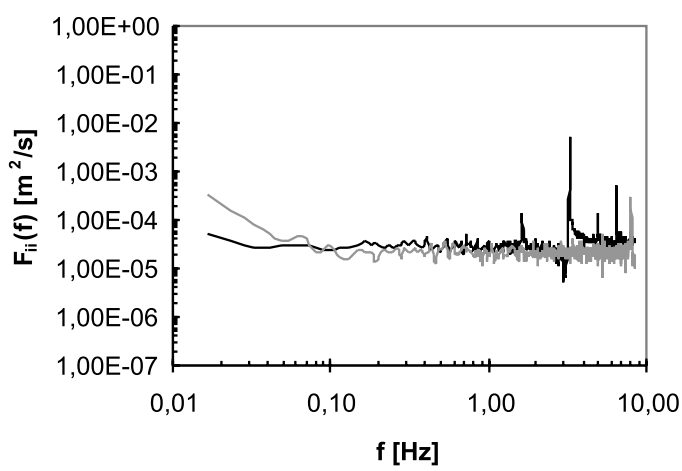

$-\operatorname{Re}=20-\operatorname{Re}=120$ a) CMC, $L 1 / 2, \alpha=60^{\circ}$

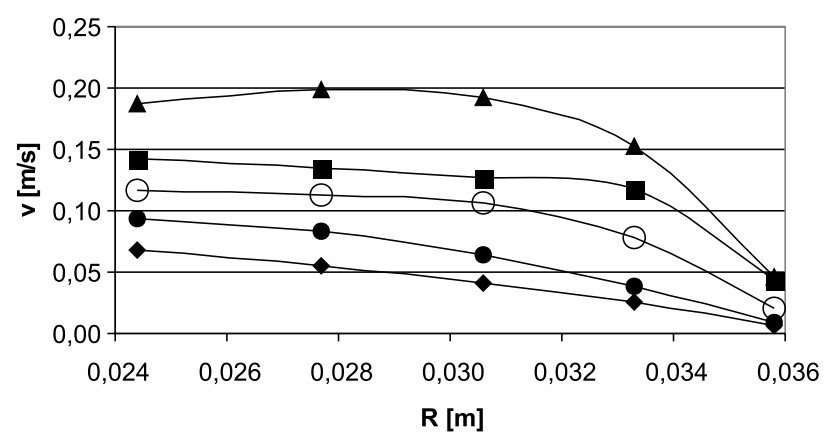

Re=20 - $-\mathrm{Re}=40-\mathrm{O} \mathrm{Re}=60 \multimap \mathrm{Re}=80 \multimap \mathrm{Re}=120$

b)

CMC, L $1 / 2, \alpha=60^{\circ}$

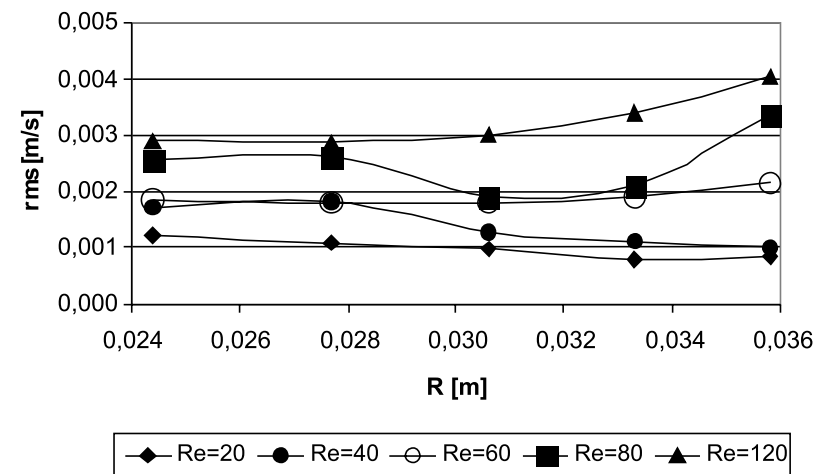

Figure 3. The fifth Kenics insert: a) axial velocity profiles; b) axial velocity fluctuations

CMC, KM, L 1/2, $\alpha=60^{\circ}, R=0,0244 m$
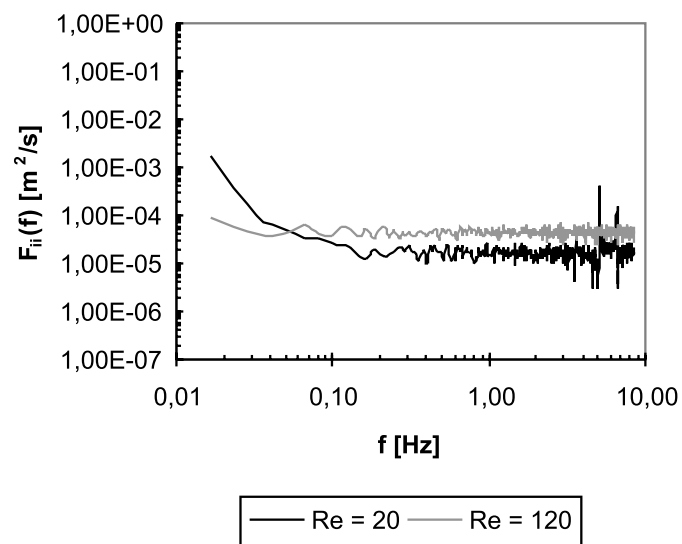

CMC, KM, L 1/2, $\alpha=90^{\circ}, \mathrm{R}=0,0244 \mathrm{~m}$

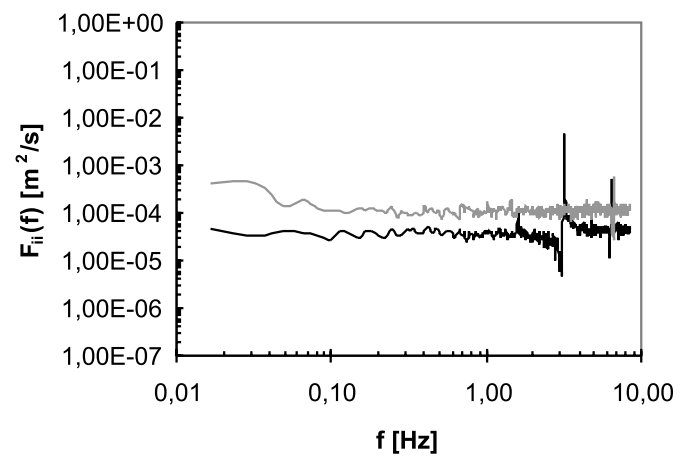

$-\operatorname{Re}=20-\operatorname{Re}=120$

Figure 4. B. One-dimensional energy spectra for two radial distances, R, and two angular position, $\alpha$; the Kenics static mixer, $\operatorname{Re}=20 \div 120$ 
Based on measurements it was observed that obtained velocity profile was typical for laminar flow. With increase of the Reynolds number, increase of the velocity fluctuations was observed. It was not possible, however, to conclude explicitly if any flow instabilities (large eddies) are present in the flow. Therefore for LDA measurement one-dimensional spectra of the kinetic energy from fluctuations of the axial component were prepared (Fig. 4).

The spectra of the fluctuations, provided information about level of the fluctuations in the observed range of Reynolds numbers (Fig. 4). It was concluded that at point $\mathrm{R}=0.0306 \mathrm{~m}$ for both angular positions, $\alpha=60^{\circ}$ and $90^{\circ}$; level of the axial velocity fluctuations for given Reynolds number was similar. The kinetic energy of the fluctuation reached level $3 \cdot 10^{-5} \mathrm{~m}^{2} / \mathrm{s}$. Moreover, for angle $\alpha=60^{\circ}$ and Reynolds number $\operatorname{Re}=20 ; 40$ and for $\alpha=90^{\circ}$ for entire range of Reynolds numbers characteristic peaks were observed. For the radial position of $\mathrm{R}=0.0244 \mathrm{~m}$, the level of the averaged kinetic energy of fluctuations for $\operatorname{Re}=120$ was about a half of decade higher than for $\operatorname{Re}=20$ for both angular position $\left(\alpha=60^{\circ} ; 90^{\circ}\right)$.

The characteristic peaks in the spectrum were not found for the tangential velocity component in the Re range from 20 to 120 . Moreover, the shape of energy spectra was akin to straight line. In addition, the LDA data acquisition rate for the tangential velocity component was considerably lower than that for the axial component. On the other hand, absence of observable peaks in the spectra for the tangential component could result from specific axis direction of eddies present in the investigated flow.

\section{CONCLUDING REMARKS}

This paper presents results obtained from the anemometric velocity measurements for non-Newtonian fluid flow through the Kenics static mixer. Results were processed by FFT procedure what allowed for further evaluation of the level of the fluctuations of the axial velocity component. Level of the velocity fluctuations for given Reynolds number $(\operatorname{Re}=20 \div 120)$ remained similar regardless of the angular position, $\alpha$, or radial position, R.

The presented results can be easily used to verify all kind of CFD simulations, like large eddy simulation (LES), performed for similar conditions for the Kenics static mixer.

\section{LITERATURE CITED}

1. van Wageningen, W.F.C., Mudde, R.F. \& van den Akker, H.E.E., Numerical investigation into mixing of particle-laden flows in a Kenics static mixer, $11^{\text {th }}$ Europ. Conf. on Mixing, Bamberg, Germany, 2003, 137 - 144.

2. Wadley, R. \& Dawson, M.K., LIF measurements of blending in static mixers in the turbulent and transitional flow regimes, Chem. Eng. Sci., 2005, 60, 2469 - 2478. DOI: 10.1016/j.ces.2004.11.021

3. Jaffer, A.A., Wood, P.E., Quantification of laminar mixing in the Kenics static mixer: an experimental study, Can. J. Chem. Eng., 1998, 76, 516 - 521.

4. Adamiak, I. \& Jaworski, Z., Badania eksperymentalne przepływu cieczy nieniutonowskiej w mieszalniku statycznym typu Kenics, Inż. Chem. i Proc., 2001, 22, 3B, 157.
5. Adamiak, I., Badania anemometryczne i modelowanie numeryczne pól prędkości cieczy w mieszalnikach statycznych, $P h D$ Thesis, Szczecin University of Technology, Szczecin 2003.

6. Fang, J.Z. \& Lee, D.J., Micromixing efficiency in static mixer, Chem. Eng. Sci., 2001, 56, 3797 - 3802.

7. Li, H.Z., Fasol, C. \& Choplin, L., Pressure drop of Newtonian and non-Newtonian fluids across a Sulzer SMX static mixer, Trans. IChemE, 1997, 75, Part A, 792 - 796. 